This item was submitted to Loughborough's Research Repository by the author.

Items in Figshare are protected by copyright, with all rights reserved, unless otherwise indicated.

\title{
Mapping the journey: visualising collaborative experiences for sustainable design education
}

PLEASE CITE THE PUBLISHED VERSION

http://dx.doi.org/10.1007/s10798-016-9365-0

\section{PUBLISHER}

(C) Springer Science and Business Media

\section{VERSION}

AM (Accepted Manuscript)

\section{PUBLISHER STATEMENT}

This work is made available according to the conditions of the Creative Commons Attribution-NonCommercialNoDerivatives 4.0 International (CC BY-NC-ND 4.0) licence. Full details of this licence are available at: https://creativecommons.org/licenses/by-nc-nd/4.0/

\section{LICENCE}

CC BY-NC-ND 4.0

\section{REPOSITORY RECORD}

McMahon, Muireann, and T.A. Bhamra. 2019. "Mapping the Journey: Visualising Collaborative Experiences for Sustainable Design Education”. figshare. https://hdl.handle.net/2134/20778. 


\subsection{Abstract}

The paradigm of design is changing. Designers now need to be equipped with the skills and knowledge that will enable them to participate in the global move towards a sustainable future. The challenges arise as Design for Sustainability deals with very complex and often contradictory issues. Collaborative learning experiences recognise that these complex issues can be addressed with the pooling of diverse knowledge, perspectives, cultures, skills and tools. Unless, however the process of collaboration is explored in detail, the opportunity for reflection, learning and improvement is lost.

This paper proposes that by introducing and analysing collaboration within third level design education, the capacity for responsible design practice can be developed, leading to a transformative shift in how designers are taught as students and subsequently practice as professionals. Over two multidisciplinary projects devised and undertaken by design students from the University of Limerick (Ireland), Hogeschool Utrecht (Netherlands) and Virginia Commonwealth University (USA), the collaborative path is mapped and critical junctions identified. From this process of mapping and visualisation, collective narratives of the overall project experience are constructed (through the eyes of the participants and planners). This leads to a greater understanding and appreciation of the benefits and limitations of the collaborative experience.

Keywords: Product Design, Design Education, Collaboration, Design Process.

\subsection{Introduction}

In third level design education there can be an over-reliance on observing outcomes as the measure of a successful project, and therefore good design. And while it is appropriate to assess the final design work in relation to acquired skills and competencies, it is often through the process that key and critical learning occurs. Similarly, it can be difficult to reflect on a process in real time as efforts are focused on completion of tasks, meeting of deadlines and managing collaborator and participant expectations. This research explores how, by reflecting on and unpacking two collaborative projects, we can create a map of the journey that details the key points along this path where successes and failures led to learning and development.

\subsection{Background}

The following section places the proposed research in the context of current research and practice. It draws together the strands of Education, Collaboration and Sustainable Development and Design, and to explore how design education at third level can develop the necessary competency and capability in designers to address the challenges of sustainability. 


\subsection{Education in Design for Sustainability}

Education for Sustainable Development [ESD] fundamentally calls for a change in the way we educate (i.e. teaching methodologies), what we teach (curriculum and subject matter) and why we do it (rationales and outcomes) (Bhamra and Dewberry 2007, Tilbury and Wortman 2004). At third level ESD aims to challenge the accepted norms and push the boundaries of educational practices. On the same premise, educating for Design for Sustainability concerns itself with the understanding and addressing of Sustainability issues as they affect the design and development of both tangible and intangible products, services and systems (Bhamra and Dewberry 2007). ESD and Design Education clearly overlap in many transformative ways. Both promote interdisciplinary approaches, urge learners to gain a holistic perspective in understanding issues and encourage creative, critical and iterative approaches to problem solving (UNESCO 2009, Hill 1998). According to fundamental ESD principles the most effective learning occurs when the process is stressed as highly as the outcomes (Sterling 2001).

\subsection{Competencies for Design for Sustainability}

For students to engage with the complex challenges involved in Design for Sustainability they will need to be equipped with a set of competencies that build on the pre-requisite abilities to think, do, analyse, plan and make decisions (Steiner and Posch 2006). Recent research conducted by a number of authors (Willard et al. 2010, Barth et al. 2007, Mochizuki and Fadeeva 2012, Parker 2010, McDonnell 2012, Wiek et al. 2011) has begun to add depth to the discussion around what the design competencies for sustainability might be. Most notably, Wiek et al (2011) highlighted the collective need for a coherent framework of competencies for application across sustainability education and research. They have attempted to amalgamate these into five competency categorisations: Anticipatory, Normative, Systems Thinking, Strategic and Interpersonal categories. These accompany the need for basic competencies in Critical Thinking and Communication that every rigorous educational program should incorporate. The most pertinent of these for collaboration are the competencies that fall under the Interpersonal umbrella. Hence, students should possess the capabilities to motivate, enable, engage, negotiate, understand and facilitate collaborative and participatory research and action. To do this successfully requires fostering and advancing students' skills in communication, leadership, empathy and holistic thinking (Ibid).

Other authors concur that the collaborative model of education should offer the basis of holistic and systems thinking required for successful sustainability integration (Parker 2010, Barth et al. 2007, de Haan 2006, Nagel et al. 2012). Collating and analysis of the literature has allowed the generation of a tentative list of competencies (Figure 1) that enables students to establish a clearer picture of what sustainability requires from designers (McMahon and Bhamra, 2015). 


\title{
Competencies for Sustainability in Design
}

\author{
Responsibility, Humility, Openness, Empathy, Critical thinking, Dialogue, Pragmatism, \\ Decision-making, Listening, Understanding, Reflection, Creativity, Flexibility, Risk-taking, \\ Acceptance of Differences, Compromise, Negotiation, Sharing, Confidence, \\ Reflection, Engagement, Participation, Interaction.
}

Figure 1: Competencies for Sustainability in Design (Willard et al. 2010, Barth et al. 2007, Mochizuki and Fadeeva 2012, Parker 2010, McDonnell 2012, Wiek et al. 2011).

The approaches to teaching and learning that facilitate the acquisition of these competencies must empower learners by encouraging participatory learning and forward thinking, all the while maximising individual development (Mochizuki and Fadeeva 2012). It is through practical projects that design students can 'translate these abstract concepts into language and action that has resonance for them' (Bhamra and Dewberry 2007, p.6). Within team projects there exists a wealth of experience, worldviews and stories that can be drawn upon which can enable students to further unpack these complexities and offer diverse perspectives in the resolution of issues.

\subsection{Design Education and Collaboration}

It is of ongoing importance that the design industry should utilise a collaborative approach where real-world research is practised by all of the stakeholders throughout the entire project, i.e. from problem definition to final design realisation (Kelley 2000). Hence, professional designers should work within teams of various experts who inform the process at the different stages. Designers recognise the richness of experience that can come from creating dialogue between these partners, whether they are experts, end-users, or social collaborators (Hill 1998). The benefits of expanding the designers' surroundings and influences cannot be undervalued according to the research conducted by Lau (2007) and Cho \& Cho (2014). University courses with direct links to the external society encourage interaction, deeper understanding and 'real world' learning (Orr 1994, Warburton 2003, Sterling 2001).

Teams are of major importance in any organisational context because, with increasing complexity, groups of individuals can work together in order to provide solutions to problems they cannot solve on their own (Stempfle and Badke-Schaub 2002). Multidisciplinary team-work, although well practiced in industry, is not always implemented effectively in education (Design Council 2007, Davis 2008). Progressive perspectives of learning indicate that learning is less a solitary act and more about the collaboration with others to pool knowledge, skills and tools (Jonassen et al. 2006). The advantage is that individuals take a more holistic approach to projects with a good understanding of other specialisms, thus enabling them to work effectively with colleagues. An additional benefit is mutual learning, where designers learn about other disciplines and those from other disciplines learn about design (Design Council 2007). It is within cross-disciplinary and collaborative project work that a real opportunity now exists to find methods of bridging and reconciling the 'disparate discourses, traditions and methodologies' of sustainable development and sustainability education (Warburton 2003, p.1). 


\subsection{Contexts for collaborative learning}

Collaborative learning emerges when individuals interact with others to create knowledge by discussion, information sharing and active participation (Leidner and Jarvenpaa 1995). It is a cyclical process of consultation, negotiation, compromise, decision-making, agreement and reflection (Chiu 2002). The advantages of working in teams are clear. For example, the depth and variety of collective knowledge at hand and the diversity offered by individual perspectives all enhance the effectiveness of shared workloads. The success of a team is built on energy, trust, openness and a 'pervasive sense of possibility' (Scharmer 2007). Once the interpersonal foundations are in place, the members need to establish what outcomes, goals, roles and interdependencies will exist within the team (Kvan 2001). These scaffolding structures ensure that the potential of the collaboration is maximised.

From an analysis of the literature on collaboration, certain criteria have been identified that have an impact on how successful or unsuccessful the collaborative experience will be. Amongst these criteria are: interpersonal ties (Hansen 1999, Lesser 2000); the role of the individual (Schön 1983, Cheng and Kvan 2001); compromise (West 2002); holistic thinking (Engestrom 2001, Senge et al. 2005); sharing ideas (Paulus 2002, John-Steiner 2000) and positivity (Scharmer 2007). Both Synergy and Communication/Dialogue have been identified as key contributors toward the collaborative process and these are explained in more detail below.

\subsubsection{Synergy}

Synergy is the ability to combine perspectives, resources and skills within a team of people (Lasker et al. 2001). It goes beyond the basic sharing of resources and into a situation where the whole is of greater significance than the sum of its parts. Essentially, finding synergy ensures that a collaborative team can create something 'new and valuable' by working towards a common and agreed goal (Ibid). Lasker (2001) cautions that synergy can be very difficult to determine within collaborations and as such the efforts to 'measure' it have focused on the individual components within the collaboration. By focusing on the individual the interactions between the members of the team are often overlooked. The emphasis, when evaluating the impact of collaboration, therefore should be focused on the collective rather than the individual experience. Here the synergy of a team is reflected in how the individual skills, resources and perspectives combine to strengthen and enrich the team.

\subsubsection{Communication}

Communication between the participants is critical in collaboration. Having the ability to communicate effectively with a variety of people from different backgrounds, and often different geographical locations is an invaluable skill in making sure collaborations are successful. The participants must understand the language and behaviour of the others involved in order to effectively share and create new knowledge (Valkenburg and Dorst 1998). Communication is also important for resolving the practical issues of sharing information, decision-making and co-ordinating tasks (Chiu 2002). Designers need to learn the core communication skill of talking 'with one another rather than past one another' (Eagan et al. 2002, p.49). The quality of the decision-making hinges on the effectiveness of communication in design collaborations, which impacts directly on the processes of consultation, negotiation, evaluation and confirmation (Chiu 2002).

Collaborative teams are comprised of a group of individuals who are working towards a collective goal. Hence, the individuals often need different information or types of communication to fulfil their portion of the task. This constraint can add complication to the process as the different strands of communication get 'tangled' in each other, which may lead to misunderstanding and confusion. Chiu (2002) recommends organising the people, the technology and their communication paths within the collaboration to assist teams in sharing information and solving specific problems. In contrast, designers and sustainability practitioners need to be comfortable with, on occasions, incomplete, contradictory and 'messy' processes in order for them to develop capacity for 'wicked' problem solving (McDonnell 2012, Wals 2010). So a semi structured approach where external individuals can facilitate communication if the teams are struggling, could be the best for projects within a learning context. Dialogue and communication don't always have to be positive and encouraging. A healthy amount of debate, critical commentary, analysis and arguing is beneficial to taking advantage of, and finding a balance between, the diverse opinions of the team members (Sobol 2012). 


\subsection{Reflecting on the collaborative process}

Unfortunately, the notion of a collaborative approach in education, while it may be desirable, can be challenging to implement. Practitioners often fall back into their specific disciplines without recognising the need for a holistic approach (Clark et al. 1995). The key problem with this type of approach may be that the compromises are too great on both sides; hence no parties feel their specific needs are being met. What is required is a means of highlighting the connections and interdependences that already exist between the disciplines and to find ways of building new connections that make sense to all participants. Being cognisant of the key concepts, the scope, limitations and complementarity that collaboration may bring is crucial to successful co-operation. A real opportunity now exists to find methods of explicating and reconciling the diverse voices and perspectives in order to generate a true trans-disciplinary approach that offers an overview of the variety of perspectives involved, thus leading to a clear vision of the whole.

There is no denying the need for collaboration between disciplines for learners to understand the systems nature of Sustainable Design and to recognise the connections between the various stakeholders within this system (Huckle and Sterling 1996). In order to resolve any complex issues a variety of opinions and a diversity of skills are required to ensure the solution is both valid and viable.

The challenges of collaboration, as described above, can be far outweighed by the benefits it can bring. These benefits include an appreciation of diverse perspectives; the ability to critically evaluate, synthesise and analyse diverse perspectives; the improved capacity for change and ambiguity; more creative holistic and broader thinking capabilities; increased humility and empathy; listening and communication skills and assuming responsibility whilst working together (Eagan et al. 2002, Warburton 2003). Research has even shown that it is in the struggle to deal with the complexity of collaboration that effective team work and the generation of innovative solutions lie (Denton 1997). Therefore, innovation can be positively harnessed to apply design driven approaches to the challenge of sustainability.

\subsection{Method}

This paper uses two distributed collaborative projects as case studies to explore, understand and reflect on the collaborative process in real-time. These two phases of Action Research form part of a larger PhD study completed in 2013 which explored the building of design capacity for social sustainability through collaborative processes (McMahon 2013). The findings from these two project experiences were collated and mapped into a visual timeline. This timeline presented an overview of the entire process for reflection and discussion with key stakeholders during and after completion of the project.

Action Research [AR] was chosen as a methodology for a number of reasons. Firstly AR assists in real- world problem-solving by expanding knowledge and linking theory to practice, in an effort to gain clarity on often complex social situations (Baskerville and Wood-Harper 1996, McKay and Marshall 2001). It is an iterative process where cycles of development, implementation, evaluation and modification lead to continuous improvement, reflection and considered change. The AR model, in this context, was ideal for the researcher in evaluating whether, and in what way, changes in the structure and delivery of a design project influences learning (Jupp 2006, McNiff and Whitehead 2006). Additionally AR, as a process, is embedded in collaboration and does not involve researching 'on' other people. Rather it is research by particular people on their own work, to help them improve what they do and how they do it (Cohen et al. 2000, McKernan 1996). Given the people centred emphasis of AR the outcomes often take the form of case studies or, as in this instance, stories (Norman and Roberts 2001).

\subsection{Collaborative Project Details}

The first round of AR (Project 1) was comprised of collaboration between Product Design undergraduates at the University of Limerick [UL] and Co-Design students studying at Hogeschool Utrecht [HU] with a brief to reshape experiences for a long haul flight crew, and to change behaviour for positive impact. The main aim of the second project (Project 2), between Multi-Disciplinary students (Art, Humanities \& Social Sciences, Engineering, Business and Marketing) at Virginia Commonwealth University [VCU] and Product Design students at UL, was to explore the broad area of food packaging and to identify areas of opportunity across any sector 
or user group. These open and 'real-world' project briefs build on the hypotheses which suggest that the starting point of a successful collaboration is 'open-ended and authentic design tasks or problems that force students to confront the multi-disciplinary character of designing practice' (Lahti 2007). Both briefs involved participation by industrial partners with the themes addressing real world problems proposed by these partners.

\subsection{Logistics}

The teams were comprised of students from both participating countries, and over the four week duration they used synchronous and asynchronous methods of communication including Skype, online Blogs, desktop sharing software, cloud storage and instant chat. By creating these 'virtual studios' they could work together to meet the deliverables set out in the brief in spite of different time zones and geographical locations.

\subsection{Analysis}

The data from the two projects were gathered using a number of different methods. Project diaries were compiled by each team throughout the project using Wordpresstm blogging software. Video and audio recordings were made at all of the presentations and at a sample of the individual group meetings. Post project Reflection Sessions and team focus group were held to gather insights from the individual and team experiences. The audio recordings from the reflection sessions, focus groups and observations were transcribed and the web-based information, field notes and participant diaries formatted into summary sheets. The quantity and depth of the qualitative data gathered, resulted in the production of thick descriptions of each team's experiences. The task of communicating the findings in an accessible way became an integral part of the analysis process.

Once the data from the various sources was collated, it was coded over three levels of coding (Open, Axial and Consolidated) as illustrated in Figure 3 below. The data across all three phases provided a wealth of information and resulted in a number of useful observational insights. The feedback centred on the experiences of the participants and the planners/facilitators which varied from extremely positive to negative. A visual timeline was created for each team, thus enabling the meaningful collation of the data from each of the data sources. By mapping out the project timelines and the subsequent project paths, a collective narrative of the overall project experience, through the eyes of the participants and planners, was constructed. Constructing this collective narrative, from the individual's and team's data, enabled the examination of how the individual skills, resources and perspectives combined to build the team synergy (Lasker 2001). Figures 2 and 3 below show the process of collating and coding the research data and building collective narratives that are illustrated through the visual timelines. 

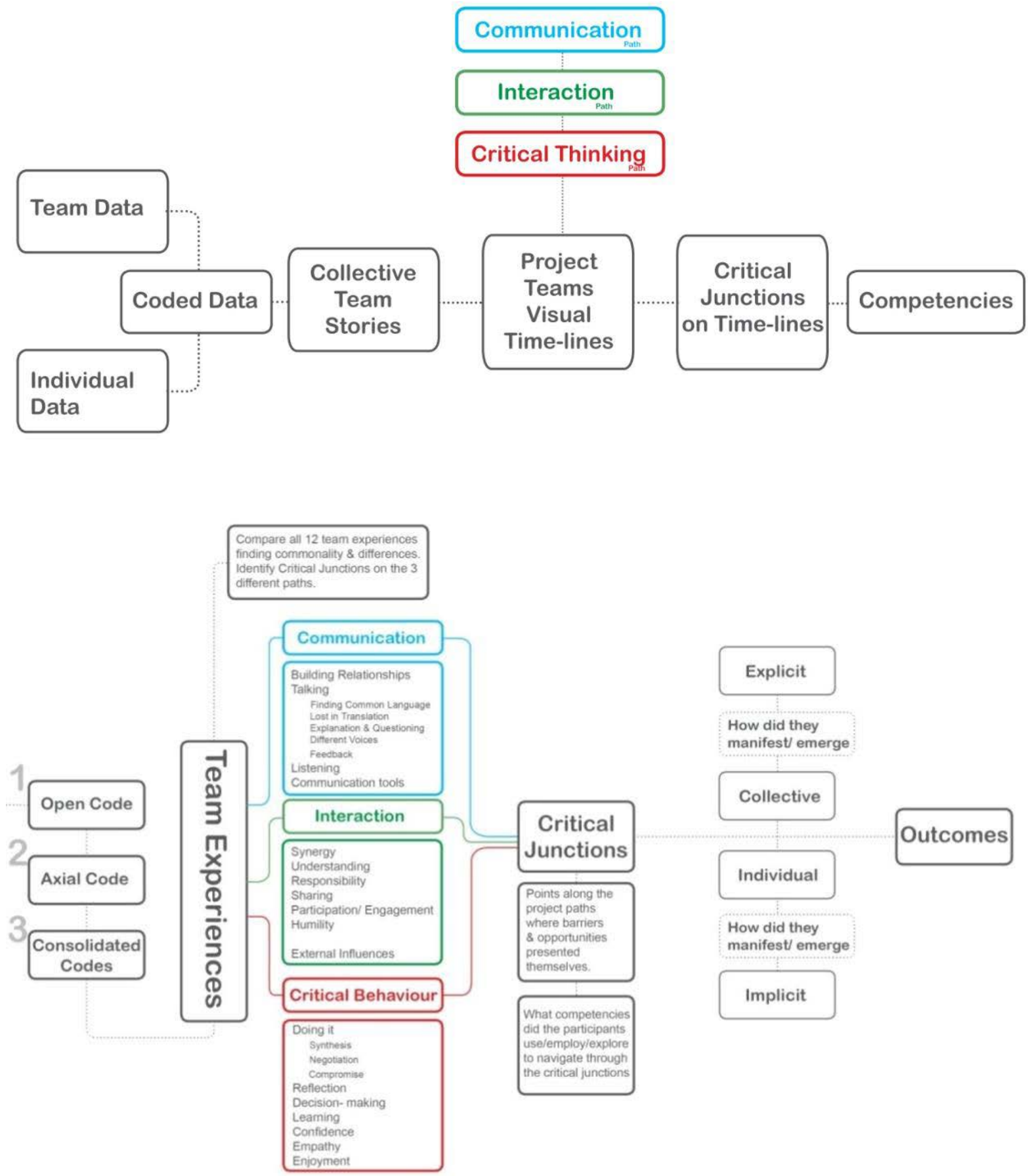

Figure 2 \& 3: Organisation, collation and analysis map of the research data.

\subsection{Explaining the Timeline}

While each project produced different results and the participants had different experiences, commonalities were observed. When the team timelines were examined and the corresponding data analysed definite patterns emerged ${ }^{1}$. The project processes clearly divided into three distinct but parallel paths: the

${ }^{1}$ A full analysis of the data including extracts and samples can be found in McMahon, M. (2013), Designed from the inside out: developing capacity for social sustainability in design through collaboration, https://dspace.lboro.ac.uk/2134/12121 
Communication Path (blue); the Interaction Path (green) and the Critical Thinking Path (red) (see Figure 4).

Along these paths, certain decisions were made and behaviours or actions became evident. These points or 'critical junctions' caused a resultant shift in the project path. The critical junctions proved significant due to the emergence of specific competencies that the participants employed (as individuals or as teams) to help them navigate beyond problems or issues. Building the timeline also enabled the identification of a multitude of ways in which the teams negotiated through the critical junctions along their project paths, for example through conversations, sketching, prototyping, conversations (real-time and virtual), and arguments. Mapping the evaluation over the competency framework allowed us to ascertain what competencies emerged and when, at these critical junctions. A sample of these 'visual time-lines' are displayed in Figure 4 and Figure 5 below. Figure 4 shows one team's timeline along with an exploded version of the story and data behind a critical junction while Figure 5 explains the icon key for the critical junctions. 
Figure 4: Project Timelines example with sample critical junction explained.

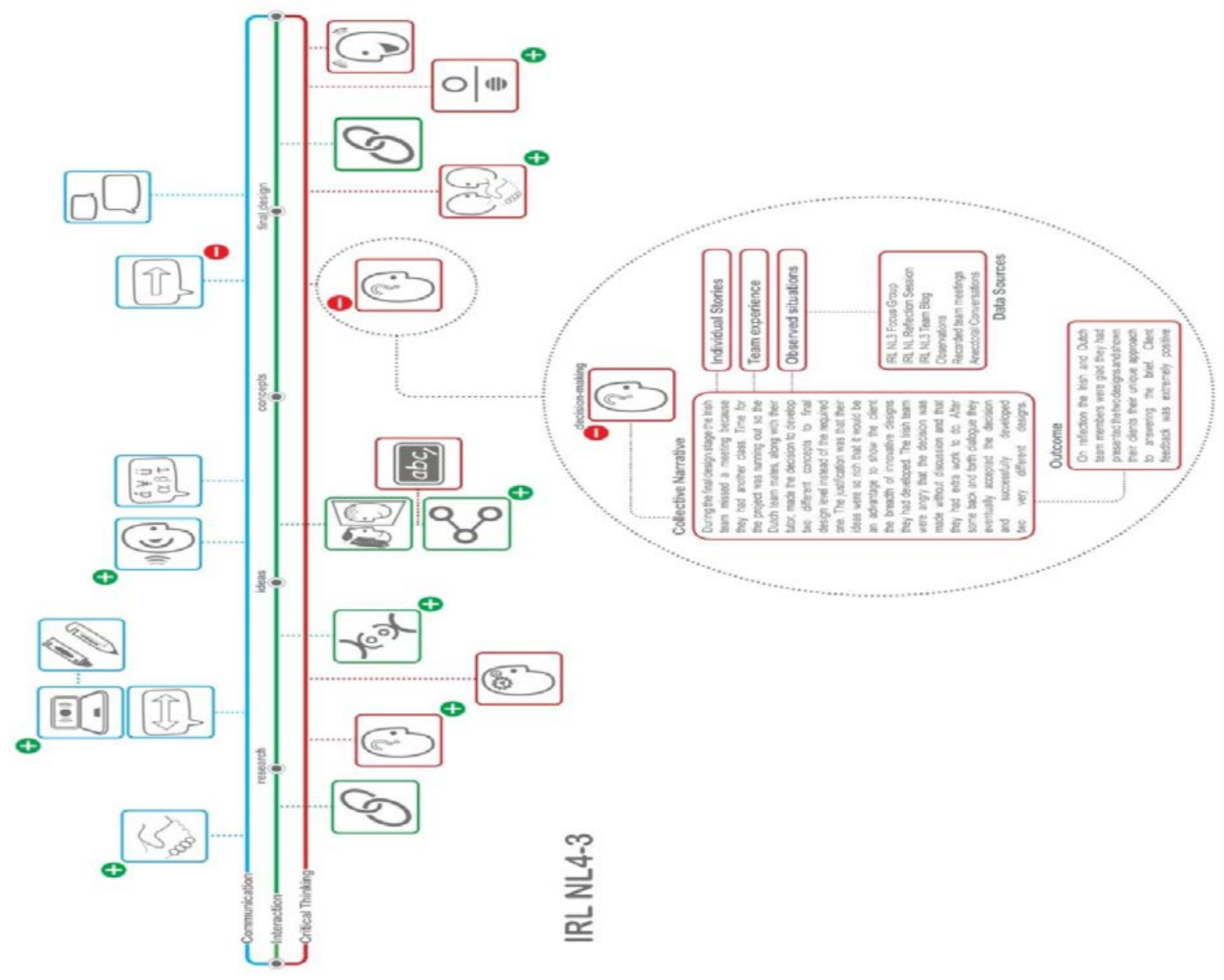



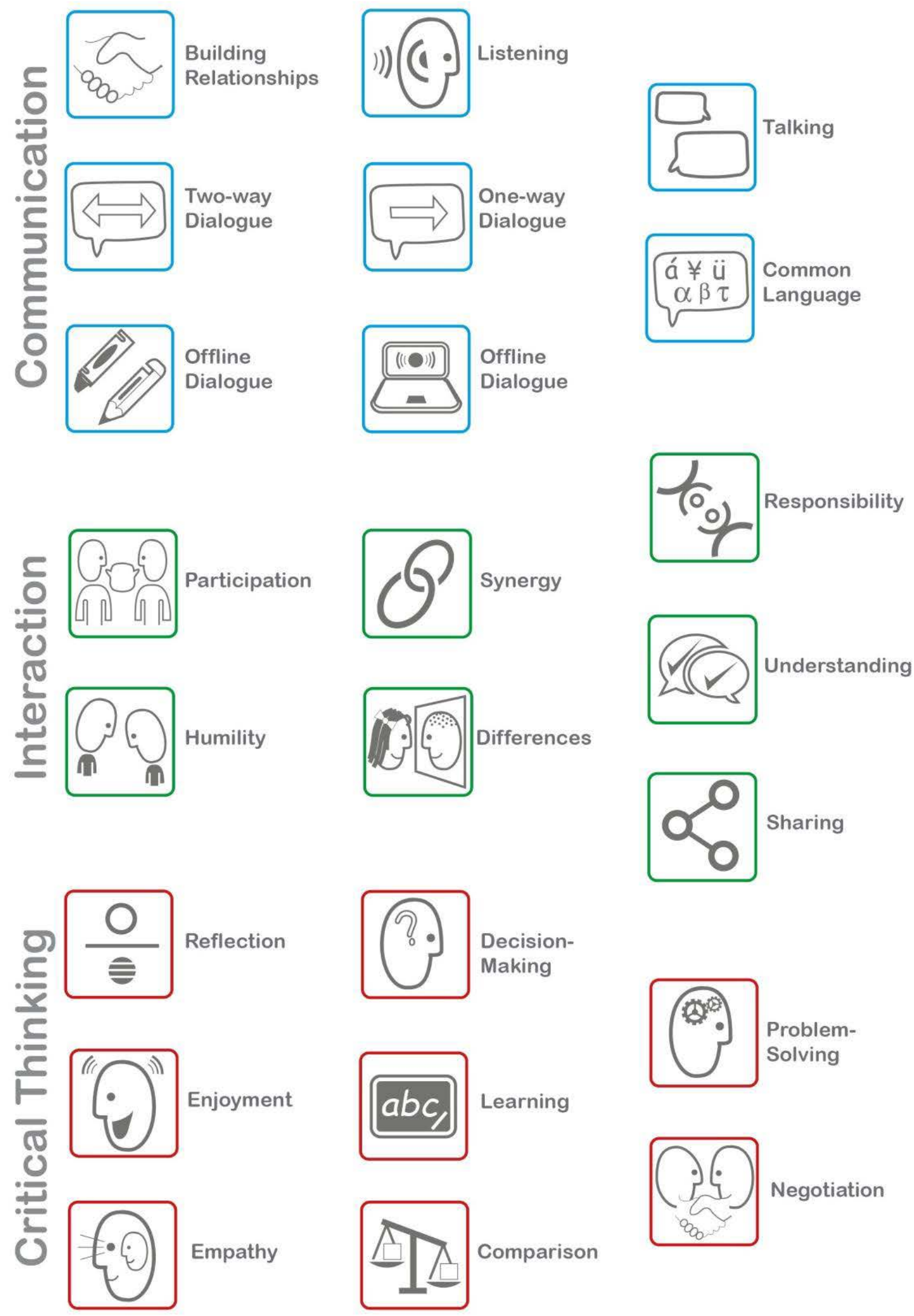

Figure 5: Icon Key for Visual Timeline 
The Communication Path deals with the communication processes of the teams throughout the project beginning with the act of getting to know their team mates through to the final presentation. The Communication path took place 'locally' with co-located participants and also in distributed environments, where teams worked using various technologies (including Skype ${ }^{\mathrm{tm}}$, Wordpress ${ }^{\mathrm{tm}}$ and Dropbox ${ }^{\mathrm{tm}}$ ) to complete the work. Both offline and online communication were considered equally important within the context of the distributed collaboration, although the former is considerably more complex.

How the teams interacted with each other to achieve the aims and fulfil the project brief, form the basis of the Interaction Paths. The individual engagement as well as the collective engagement is important. Where the individuals within the team overlapped, where they diverged and converged and what critical junctions occurred at these points of divergence and convergence became apparent. The interaction path focuses on how the individuals within the teams worked collectively to achieve the aims set out by themselves and their engagement in the project brief. Both the process of interaction and the outcomes of the critical junctions were be explored in order to understand the contexts for 'successful' collaboration.

The Critical Thinking Path describes the 'culturally produced and socially supported' ways of seeing which shaped and guided the actions of the individuals and the teams (Carr and Kemmis 1986). The critical junctions along this path are comprised of the instances where the participants re-evaluated their existing habits to generate new understanding and knowledge. This path enabled the researchers to also examine how the participants took a journey of exploration to acquire this new knowledge, while also looking anew at existing knowledge. "Thinking critically is a shift in perspective, even if it is just a small shift. It is about increasing our own awareness of how we think, letting go of strongly held beliefs and creating a new mental model, a new mind-set" (Sofo 2004).

\subsection{Discussion}

The evaluation of these two projects, The Flight Crew Rest and the Food Packaging, revealed that collaboration isn't a single path. It is a series of co-linear paths that diverge and converge along the project process as participants attempt to deal with the complexity of conflicting voices (Figure 6). By establishing and illustrating the project timelines, it has allowed us to visualise these paths. The timelines have captured how the smaller instances, or critical junctions, combine to provide a holistic narrative of each team's experiences. These critical junctions provided insights, identified relationships, trends and generalisations that occurred across both projects. For example, there were similarities and differences noted in how relationships were formed and maintained as well as the nature of these inter-team relationships, moving from strong, positive team structures through to weaker, negative structures. Other examples of key insights were how teams communicated (talked and listened), found common language (questioned, argued, negotiated and clarified) and learned from each other, as well as how the teams capitalised on the disciplinary and cultural differences, or allowed them to become obstacles that hindered the progress of their team. 

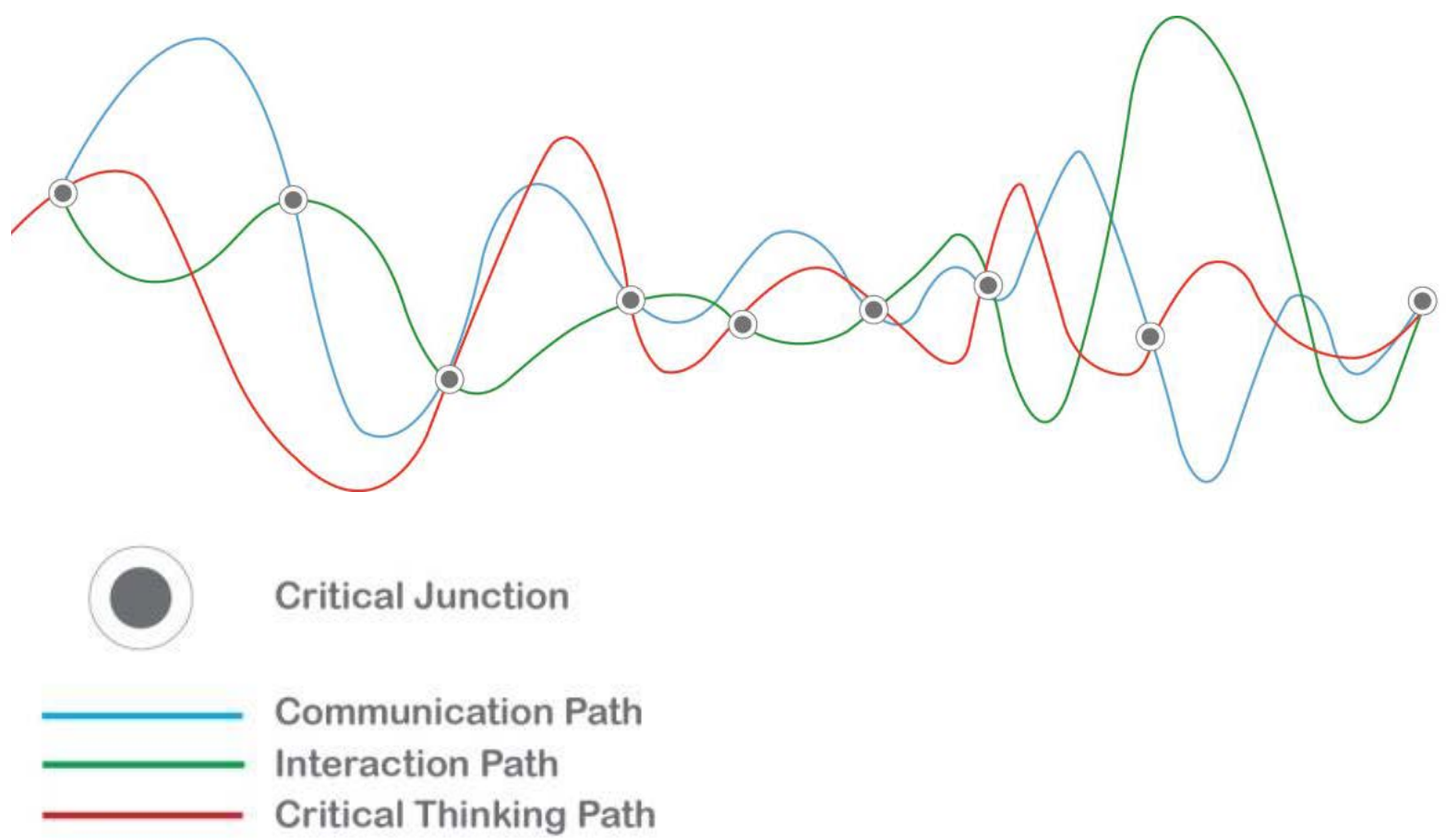

Figure 6: Visual Representation of the complexity and interdependencies of the project paths.

In spite of the project parameters being the same for every team (e.g. project brief, schedule and deliverables), each team's experiences were unique, as they worked through their process in a variety of ways and organised and interacted with their team mates differently. The Visual Timelines allow project facilitators (in this case design tutors) to trace the acquisition of the necessary competencies while each project is ongoing and then use it for reflection upon completion of the project. The critical junctions pinpoint instances of interest or note along the project process path. By pinpointing these instances, or junctions, facilitators can explore where the project was successful or unsuccessful in order to learn what behaviours were present, what tools/techniques/ competencies were employed or emerged when the participants needed to navigate through the process. Stories can be constructed around the emergence of these competencies and by this process, facilitators and participants can pinpoint the conditions that are conducive or prohibitive to effective collaboration.

This unique instrument can be both a learning tool as well as a means of evaluating the impact collaborative projects can have on a particular group of participants under certain conditions. By creating these timelines, design educators and practitioners can explore the emergence of the competencies over time and across consecutive projects. And perhaps, more importantly, the timeline instrument can enable participants to construct deeper meaning throughout their projects and note the reflection of their actions in other participant's eyes (e.g. positive, constructive feedback on a finished product).

Moving from the general broad based competencies outlined in the literature (Mochizuki and Fadeeva 2012, Parker 2010), the evaluations from this research indicate that focusing on a smaller range of competencies could be more valuable. This may allow the participants to break down large complex problems into manageable 'chunks' and attain success on a smaller scale, while ensuring that they are engaged and develop the competencies to a greater depth. In interpreting the results we can see that a number of the competencies were evident more frequently at the critical junctions along the project paths. The timeline has demonstrated how interlinked and inter-dependent the competencies are. Some are explicit and others are implicit and highly reliant on the over-arching competencies to emerge, thus creating a web of competencies that are closely linked and multi-layered. 
While you cannot argue against awareness of the holistic picture for sustainable design education, the timeline research findings indicate that designers may need to begin with smaller projects which introduce the competencies threaded through the design brief and project structures. The competencies can then be developed by taking the necessary time required for mastery to evolve, without too much confusion, complication, or stress. These smaller projects could be 'bricked' together and increased in complexity so the development of the competencies happens over a longer period of time, leading to a more lasting and transformative impact. Accumulation of these small scale projects and interventions may contribute effectively to larger global change effects over time. Recording the progress and process throughout the timelines leaves a permanent record for review and reference.

\subsection{Conclusion}

The reality of developing competency in design for sustainability is demonstrably more complex than 'doing' a design project, fulfilling a brief, or listing a set of desired learner characteristics. For all, or some, of the competencies to be attained to any level designers must be given the correct contexts and opportunities for restructuring old and acquiring new knowledge. The competencies emerged when the designers were exposed to new and different perspectives through collaboration, and were challenged to navigate through the diverse opinions and processes that these perspectives presented.

There is very little literature drawing together the three strands of design education, collaboration and design for sustainability. Unpacking the experiences through the visual timelines has identified a number of interesting issues and insights (such as the inter-connectedness of competencies, the need to build competency over time and recognition of the differences within and between teams on any given project), which demonstrate why collaboration is important in the development of sustainable practice in design. Implementing Sustainable Development is a complex and extremely difficult process, given the wicked nature of the problems associated with it. The timelines, while not the only measure, can help to identify how, where and why collaboration can help work towards sustainability in design. Using this process, the behaviours and actions of the participant designers, working either as individuals or in teams, can be thoroughly explored.

The collaborative process is complex as all participating parties (planners, facilitators and designers) struggle with the diversity of voices, the development of a common language, and the negotiation of solutions that reflect the variety of disciplines involved. In a quick and easy way, the visual timelines (see Figures 4 and 5) are a useful tool to help participants and facilitators to reflect effectively on processes that can often be hurried and chaotic within an educational situation. In addition, through the process of slowing down, reflecting in real time and creating a tangible timeline, designers can begin to see how their processes can contribute to the construction of better products, thus contributing to a more sustainable future. 


\section{References}

Barth, M., Godemann, J., Rieckmann, M. and Stoltenberg, U. (2007), Developing key competencies for sustainable development in higher education. International Journal of Sustainability in Higher Education, 8(4), 416-430.

Baskerville, R. L. and Wood-Harper, T. (1996), A critical perspective on action research as a method for information systems research. Journal of Information Technology, 11. 235-246.

Bhamra, T. and Dewberry, E. (2007), Re-Visioning design priorities through sustainability education. In International Conference on Engineering Design ICED '07, 28-31 August 2007, Paris.

Carr, W. and Kemmis, S. (1986) Becoming Critical: Education, knowledge and action research. London: The Falmer Press.

Cheng, N. Y.-w. and Kvan, T. (2000), Design Collaboration Strategies. In 4th SIGRADI, Rio de Janeiro.

Chiu, M.-L. (2002), An organizational view of design communication in design collaboration. Design Studies. 23(2), 187-210.

Cho, J.Y \& Cho, M-H, (2014), Student perceptions and performance in online and offline collaboration in an interior design studio. International Journal of Technology and Design Education. 24, 473-491.

Clark, N., Perez-Trejo, F. and Allen, P. (1995), Evolutionary dynamics and sustainable development: a systems approach. Aldershot: Edward Elgar.

Cohen, L., Manion, L. and Morrison, K. (2000), Research Methods in Education, 5th ed. London \& New York: Routledge Falmer.

Davis, M. (2008), Why do we need doctoral study in Design?. International Journal of Design, 2(3), 71-79.

de Haan, G. (2006), The BLK '21' programme in Germany: a 'Gestaltungskompetenz'- based model for Education for Sustainable Development. Environmental Education Research. 12(1), 19-32.

Denton, H. (1997), Multidisciplinary team-based project work: planning factors. Design Studies, 18, 155-170.

Design Council (2007), Lessons from America: Report on the Design Council. London. Higher Education Funding Council for England.

Eagan, P., Cook, T. and Joeres, E. (2002), Teaching the importance of culture and interdisciplinary education for sustainable development. International Journal of Sustainability in Higher Education. 3(1), 48-66.

Engestrom, Y. (2001), Expansive learning at work: toward an activity theoretical re-conceptualisation. Journal of Education and Work. 14(1), 133-156.

Hansen, M. T. (1999), The search-transfer problem: the role of weak ties in sharing knowledge across organisation subunits. Administrative Science Quarterly. 44.

Hill, A-M. (1998), Problem Solving in Real-Life Contexts: An Alternative for Design in Technology Education. International Journal of Technology and Design Education. 8, 203-220.

Huckle, J. and Sterling, S., eds. (1996), Education for Sustainability. London: Earthscan.

John-Steiner, V. (2000), Creative Collaboration. New York: Oxford University Press Inc.

Jonassen, D. H., Strobel, J. and Lee, C. B. (2006), Everyday problem solving in engineering: Lessons for engineering educators. Journal of Engineering Education. 95(2), 1-14.

Jupp, V., ed. (2006) The SAGE dictionary of social research methods. London: SAGE Publication. 
Kelley, T. (2000), The Art of Innovation. New York: Doubleday.

Kvan, T. (2001), The pedagogy of virtual design studios. Automation in Construction. 10, 345-353.

Lahti, H. (2007), Collaboration between students and experts in a virtual design studio. Journal of Design Research. 6(4), 403-421.

Lasker, R. D., Weiss, E. S. and Miller, R. (2001), Partnership Synergy: A practical framework for studying and strengthening the collaborative advantage. The Millbank Quarterly. 79(2), 179-205.

Lau, K.-W. (2007), Establishing creative-friendly space for design thinking in shared virtual reality in tertiary design education. In International Association of Societies of Design Research, Hong Kong 12-15.11.2007.

Leidner, D. E. and Jarvenpaa, S. L. (1995), The use of Information Technology to enhance management school education: a theoretical view. Management Information Systems Quarterly. 19(3), 265-291.

Lesser, E. L. (2000), Knowledge and social capital. Woburn, MA: Butterworth-Heinemann.

McKay, J. and Marshall, P. (2001), The dual imperatives of action research. Information Technology \& People, 14(1), 46-59.

McDonnell, J. (2012), Accommodating disagreement: A study of effective design collaboration. Design Studies. 33, 44-63.

McKernan, J. (1996), Action Research: A handbook of methods and resources for the reflective practitioner $\left(2^{\text {nd }}\right.$ Edition). London: Kogan Page.

McMahon, M. (2013), Designed from the inside out: developing capacity for social sustainability in design through collaboration, https://dspace.lboro.ac.uk/2134/12121

McMahon, M. \& Bhamra, T. (2015), Social Sustainability in Design: Moving the Discussions Forward, The Design Journal, 18:3, 367-391.

McNiff, J. and Whitehead, J. (2006) All you need to know about Action Research, London: SAGE Publications Ltd.

Mochizuki, Y. and Fadeeva, Z. (2012), Competences for sustainable development and sustainability: significance and challenges for ESD. International Journal of Sustainability in Higher Education. 11(4), 391-403.

Nagel, R. L., Papapas, E. C. and Pierrakos, O. (2012), On a vision to educating students in sustainability and design- The James Madison University School of Engineering approach. Sustainability. 4, 72-91.

Norman, E.W. and Roberts, P.H. (eds) (2001), Design and technology educational research and curriculum development: the emerging international research agenda. Loughborough: Loughborough University.

Orr, D., W. (1994), Earth in Mind. Washington DC: Island Press.

Paulus, P. B. (2002), Different ponds for different fish: A contrasting perspective on team innovation. Applied Psychology: An International Review, 51(3), 394-398.

Parker, J. (2010), Competencies for inter-disciplinarity in higher education. International Journal of Sustainability in Higher Education, 11(4), 325-338.

Scharmer, O. C. (2007), Theory U: Learning from the future as it emerges. Cambridge, MA: Society of Organisational Learning.

Schön, D. (1983), The Reflective Practitioner. USA: Basic Books.

Senge, P., Scharmer, C. O., Jaworski, J. and Flowers, B. S. (2005), Presence, Exploring profound change in people, organisations and society. London: Nicholoa Brealey Publishing. 
Sobol, D. (2012), Innovation is about arguing, not brainstorming. Here's how to argue productively. Fast Company. available: [accessed 03.03.2012].

Sofo, F. (2004), Open your mind: the 7 keys to thinking critically. St.Leonards, NSW: Allen \& Unwin.

Steiner, G. and Posch, A. (2006), Higher education for sustainability by means of trans-disciplinary case studies: an innovative approach for solving complex real-world problems. Journal of Cleaner Production, 14, 877-890.

Stempfle, J. and Badke-Schaub, P. (2002), Thinking in design teams- an analysis of team communication. Design Studies. 23, 473-496.

Sterling, S. (2001), Sustainable Education: Revisioning Learning and Change, Totnes, Devon: Green Books.

Tilbury, D. and Wortman, D. (2004), Engaging people in sustainability, Commission on Education and Communication. Gland and Cambridge: IUCN.

UNESCO (2009) 'UNESCO.org', [online], available: http://portal.unesco.org/education/en/ev.php URL_ID=27234\&URL_DO=DO_TOPIC\&URL_SECTION=201.htm [accessed 24.06.2012].

Wals, A. E. J. (2010), Mirroring, Gestaltswitching and transformative social learning: Stepping stones for developing sustainability competence. International Journal of Sustainability in Higher Education. 11(4), 380390.

Warburton, K. (2003), Deep learning and education for sustainability. International Journal of Sustainability in Higher Education. 4(1), 44-56.

West, M. A. (2002), Sparkling fountains or stagnant ponds: An integrative model of creativity and innovation implementation in work groups. Applied Psychology: An International Review. 51(3), 355-424.

Wiek, A., Withycombe, L. and Redman, C. L. (2011), Key competencies in sustainability: a reference framework for academic program development. Integrated Research System for Sustainability Science, 6,203-218.

Willard, M., Wiedmeyer, C., Flint, R. W. and Weedon, J. S. (2010), The Sustainability Professional: 2010 Competency questionnaire report. International Society of Sustainability Professionals.

Valkenburg, R. and Dorst, K. (1998), The reflective practice of design teams. Design Studies, 19, $249-271$. 